\title{
Comparative analysis and case study on the absolute value accounting of mineral resources
}

\author{
XU Shuang ${ }^{1}$, LIU Chunxue ${ }^{2, a}$ \\ School of Urban and Environment , Yunnan University of Finance and Economics, 650221 Kunming ,P.R. China
}

\begin{abstract}
Absolute value is an important part of the natural value of mineral resources, and it is also an important manifestation of the exhaustion of mineral resources. However, the calculation of the absolute value of mineral resources is greatly affected by changes in the market and it is easy to draw distorted results. In order to reflect the difference in absolute value of mineral resources at different development stages and the true value of the absolute value of mineral resources. This article is based on the analysis of the causes of the error in measuring the absolute value of mineral resources. The development stage coefficient, the highest price, and the industry discount rate were introduced in the model for measuring the absolute value of mineral resources. At the same time, it is combined with actual cases for comparative analysis. The improved calculation method can better reflect the true level of the absolute value of mineral resources. The accuracy of the measured results has also been improved. At the same time, it also reflects the future expected and risk levels of the measurement results. In the process of mineral resource management, it is conducive to more reasonable realization of the owner's rights and interests. It can also improve the utilization efficiency of mineral resources. It can also better coordinate intergenerational interests and promote the sustainable development of the mineral resources industry.
\end{abstract}

\section{INTRODUCTION}

In social development, mineral resources have provided most of the energy, industrial raw materials, and agricultural production materials. It is also the material basis for human survival and development. However, the mineral resources of our country have always been based on physical accounting, but their value accounting is less. This has caused the chaotic exploitation ,the serious destruction and waste of mineral resources. This also leads to low output efficiency and high consumption of resources. With the advance of ecological civilization construction in our country, asset management and supervision of natural resources are continuously strengthened. Accounting research on the value of natural resources (especially absolute value) is becoming more and more urgent. Its purpose is to reduce the waste and loss of mineral resources.

At present, the research on the value of mineral resources mainly focuses on the source of value, value measurement, value assessment, etc.(Yang Hua et al., 2010; Li Yuan et al., 2010; Fan Zhenlin et al., 2017; Pu Zhizhong, 2008; Jiang Jianming et al., 2017; Yan Maohua, 2010; Liu Jianfen et al., 2014; Zheng Juaner et al., 2015) [2-3, 5-6]These scholars have conducted indepth research on the labor value and relative value of mineral resources, and the absolute value of mineral resources has also been analyzed from different perspectives, (Yuan Yingju, 2009; Li Guoping, 2011)[1,7]but these studies are not sufficient. This article compares the absolute value calculation methods of mineral resources under different perspectives, and then proposes an improvement plan. At the same time, this article combines practical cases to analyze, and its purpose is to more accurately reflect the absolute value of mineral resources.

\section{Accounting method analysis of absolute value of mineral resources}

Mineral resources are naturally occurring mineral aggregates that are also useful to humans. Its properties are scarce and there are natural values. But the realization of its natural value requires the combination of geological exploration labor[4].It is generally believed that the natural value of mineral resources includes absolute value and relative value. Relative value is related to the natural endowment of mineral resources ,such as grade, composition, and mining conditions. It is easier to relate to the cost of mining. Therefore, the relative value of mineral resources can be more accurately accounted. The absolute value of mineral resources is related to the depletion of mineral resources. It is not easy to measure directly with labor and transactions, and it needs to be measured indirectly.

In different research perspectives, the absolute value of mineral resources has been given different academic titles. For example, absolute mining rent, absolute rent, Hotlin rent, scarce rent, resource consumption, depletion

\footnotetext{
${ }^{\text {a } C o r r e s p o n d i n g ~ a u t h o r: ~ c h u n x u e l i u @ y n u f e . e d u . c n ~}$
} 
or user costs, marginal user costs, etc. This article refers to these titles as the absolute value of mineral resources.

Although the method of calculating the absolute value of mineral resources is different, it is mainly measured from the perspective of income. That is to say, it is measured by the profit exceeding the inferior mineral resources. It need to discount the final value of future earnings to the present. It can be expressed by the following formula:

$$
V=\sum_{t=1}^{n}(P-C) \times \frac{1}{(1+r)^{t}}
$$

In formula (1), $V$ is the absolute value of the current mineral resources and $P$ is the price of mineral resources. Where $\mathrm{C}$ is the cost of mineral resources under conditions of inferiority; $r$ is the discount rate and $n$ is the expected life of the mine.

Among them, the value of $P$ can be the current market price of mineral resources, or the price of its substitutes. The value of $\mathrm{C}$ can be the cost of inferior mineral resources, or the marginal cost of its substitutes. Costs can include production costs, investments, taxes, etc.(Yuan Yingju, 2009); The value of $n$ may be the life of mineral resources, or the time when the price of substitutes rises to the same price level as the mineral resources they replace. The value of $r$ is generally the risk-free interest rate. The use of excess returns to measure the absolute value of mineral resources that can be more easily calculated based on price and cost. However, changes in prices and costs are largeing over time. And it is influenced by factors such as supply and demand, scientific technological progress, and economic and social development stages. This easily distorts the absolute value of mineral resources. At the same time, we need to use two parameters of income year and discount rate when discounting income. Its value is prone to bias under different future expectations. It is also easy to distort the absolute value of mineral resources. When the price volatility is large or the future expectation is wrong, the absolute value of the mineral resources will change greatly. There may even be cases where the absolute value is negative. It is difficult to better reflect the exhaustion of mineral resources. This is not conducive to the rational development and utilization of mineral resources.

\section{Improvement of Accounting Method of Absolute Value of Mineral Resources}

The absolute value of mineral resources should reflect the exhaustion of mineral resources. This depletion is determined by the long process of the geological formation of mineral resources. However, this exhaustion can exacerbate or worsen scarcity and generate excess profits. Therefore, using excess profits to measure it. However, it is vulnerable to external factors in the non-competitive market. This distorts the accurate measurement of the absolute value of mineral resources.
Absolute value of mineral resources is an intrinsic, naturally occurring, reflection of scarce value. Regardless of whether mineral resources are mined, it is an objective reality. It should reflect the intrinsic properties of mineral resources. It is used to compensate for the interests of generations and owners. It is an economic compensation for the opportunity cost and owner's equity between generations. When measuring the absolute value of mineral resources, it is necessary to consider the stages of economic and social development, the extent of changes in market prices, industry benefits, etc.

Price is the expression of value and can reflect the absolute value of mineral resources. However, many factors affect the price formation in the actual market. Among them, the most direct influence factor is the relationship between supply and demand. The indirect influence factors include the level of production technology, market structure, investment, policy orientation, economic cycle, exchange rate, inflation rate, etc. These factors cause the price of mineral resources to fluctuate greatly and distort the value of mineral resources. When the price of mineral resources is very low, scarcity is reduced, and the grade of inferior mineral resources is increased. This will lead to the absolute value of mineral resources cannot be reflected in the price. In some cases, even the absolute value of mineral resources is negative. However, when the price of mineral resources is high, scarcity increases, and the grade of inferior mineral resources decreases. This can better reflect the absolute value of mineral resources. Therefore, the use of high prices to measure the absolute value of mineral resources can better reflect its true level.

Due to the many factors that influence the price formation. High prices are not all due to the absolute value of mineral resources caused by depletion. Calculating results directly using high prices will be high. The need to exclude non-absolute value interference when selecting high prices to measure the absolute value of mineral resources. The purpose is to improve the accuracy of absolute value measurement of mineral resources. This paper uses the coefficient of economic and social development stage to do some adjustments. In order to adjust the overall non-absolute value interference in high prices.In addition, it reflects the willingness of people to pay for the exhaustion of mineral resources at different stages of economic development. Willingness to pay can reflect people's subjective recognition of the absolute value of mineral resources and is closely related to the stage of economic and social development.The level of willingness to pay will change as the stage of economic and social development changes. A simplified version of the R.Pearl S-shaped growth curve model can be used to approximately estimate the economic and social development stage coefficients[8].

$$
\ell=\frac{1}{1+e^{-t}}
$$

In formula (2), $e$ is the bottom of the natural logarithm and $l$ is the stage coefficient of economic and 
social development. $(0 \leq \ell \leq 1) \mathrm{t}$ is time. Here we use the inverse $\frac{1}{E}$ of the Engel's coefficient $E$ as the abscissa, and it represents the time period of socioeconomic development. And order $t=\frac{1}{E}-3$.The smaller the value of $\ell$, the lower the level of development. The greater the value of $\ell$, the higher the level of development. When $\ell$ is equal to 1 , Peer's growth curve reaches saturation. Development stage coefficient has a maximum value of 1 .

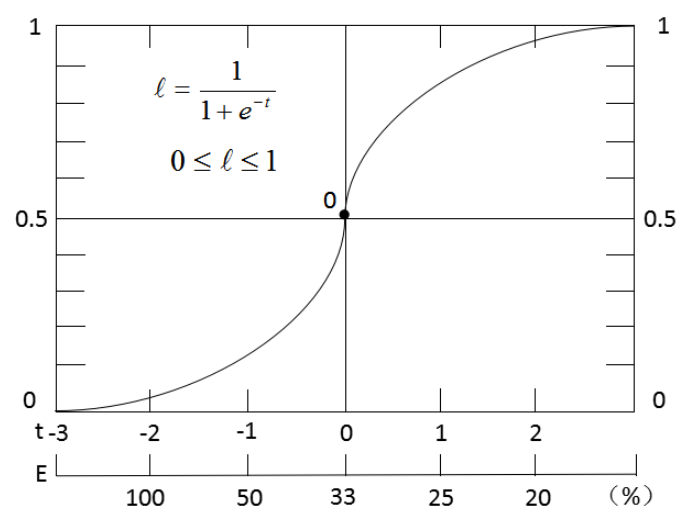

Figure 1. Using Peer Growth Curve and Engel's Coefficient to Determine Development Stage Coefficient

Therefore, the formula for calculating the absolute value of mineral resources considering the stage coefficient of economic and social development can be expressed as:

$$
V=\sum_{t=1}^{n} \ell(P-C) \times \frac{1}{(1+r)^{t}}
$$

The discount rate $r$ is the conversion rate between future expected return and current value. It is the investor's expectation of investment income and attitude toward investment risk. Different industries have different income and risk levels. Therefore, in order to better reflect the expected benefits and risks of the industry, and it is necessary to accurately determine the corresponding discount rate for each industry. At present, most of the adoption of the discount rate use risk-free interest rates (five-year treasury rate). However, there are differences in investment and financing decisions and income distribution among various industries. The present value calculated using the risk-free interest rate is high, and the industry is not well-targeted. This article suggests the selection of industry social discount rates. The purpose is to reflect the future expected benefits and risks of the mineral resources industry. It is more forward-looking to facilitate the measurement of the absolute value of mineral resources.

\section{Empirical analysis of absolute value accounting of mineral resources}

Based on the above formula for calculating the absolute value of mineral resources, the paper uses a mine in Yunnan as an example to measure the absolute value of tin mineral resources, and compares it with other methods.

A mine in Yunnan Province is a mining-oriented medium-sized mine with a mining period of 30 years. The remaining effective mining period is 10 years by 2017.According to the survey, the company's 2017 total cost of mining (including outsourcing costs) was 1.55 billion yuan. The production cost of $40 \%$ tin concentrate accounts for about $60 \%$ of its total cost. $40 \%$ tin concentrate smelting tin metal amount to 31045 tons. Unit production (tons) for $40 \%$ tin concentrate in 2015 was $28,737.58$ yuan.

According to the simplified form of the Pear growth curve model, the Engel's coefficient of $29.3 \%$ in 2017 is taken into account for calculation. Finally, the development stage coefficient $\ell$ is determined to be 0.6.In addition, according to the law of change of Engel's coefficient in China (the Engel's coefficient decreases by approximately $0.6 \%$ per year). An economic and social development stage is defined as Engel's coefficient between 25\% and 33\% (approximately 2012-2024).In addition, in the case of this paper, the determination of the coefficient of economic development stage is based on the approximation of the Engel's coefficient in 2017.This paper uses the economic and social development stage coefficient of the year to replace the economic and social development stage coefficient of the mining enterprise in the next 10 years. The remaining 7 years (2018-2024) of the 10 years of mining enterprise's remaining effective mining period happens to be within this phase of economic and social development. While the remaining three years (20252017) are affiliated with the next stage of economic and social development, this is not the focus of the case study of this paper, so no special calculation is made here.

According to the Shanghai Nonferrous Metals Trading Network, the current price (2017) of the $40 \%$ tin concentrate metal trading is 127,500 Yuan per ton. The historical highest price in the period of economic and social development (2012-2024) was 168,000 Yuan per ton (the highest in 2012). In 2015, the price of $40 \%$ tin concentrate reached a historical low of 105,000 Yuan per ton. According to the calculation formula of tin concentrate price $40 \%$ tin concentrate price $=40 \%$ tin concentrate metal trading price $\times$ tin concentrate grade ${ }^{\times}$valuation coefficient (take 0.7). The price in 2015 was 29,400 Yuan per ton, and the highest price in history was 47,040 Yuan per ton.

The discount rate is $4.22 \%$ of the risk-free rate (according to the five-year electronic bond interest rate issued in 2017). The social discount rate for the nonferrous metals mining industry is $13 \%$ (based on the 《Economy Evaluation Method and Parameters for Construction Projects》 third edition).

According to different research perspectives, the calculated absolute value of mineral resources is 
different. As shown in Table 1. The higher prices of these standards and alternatives to reach the age limit are difficult to determine. It is not feasible.

Table 1. Absolute value measurement of mineral resources from different perspectives

\begin{tabular}{|c|c|c|c|c|c|}
\hline parameter & Scenario 1 & Scenario 2 & Scenario 3 & Scenario 4 & Improved Method \\
\hline $\begin{array}{c}\text { price } P \\
\text { (Yuan per ton) }\end{array}$ & $\begin{array}{c}\text { Current price } \\
\text { in } 2017: \\
35700\end{array}$ & $\begin{array}{c}\text { Price in 2015: } \\
29400\end{array}$ & $\begin{array}{l}\text { Higher price: Difficult to } \\
\text { determine specific values }\end{array}$ & $\begin{array}{c}\text { Alternative prices }=\text { Current } \\
\text { price }\end{array}$ & $\begin{array}{l}\text { The highest price in the } \\
\text { period of 2012-2017 is } \\
47040\end{array}$ \\
\hline $\begin{array}{c}{ }_{\text {cost }} C \\
\text { (Yuan per ton) }\end{array}$ & 30005.41 & 28737.58 & l & l & 30005.41 \\
\hline $\begin{array}{c}\text { Year of } \\
\text { income } n \text { (year) }\end{array}$ & 10 & 12 & / & $\begin{array}{l}\text { It is difficult to determine } \\
\text { the replacement age }\end{array}$ & 10 \\
\hline $\begin{array}{c}\text { Discount Rate } \\
\text { Stage }\end{array}$ & $4.22 \%$ & $4.22 \%$ & / & / & $13 \%$ \\
\hline coefficient $\ell$ & / & l & / & l & 0.6 \\
\hline $\begin{array}{l}\text { Absolute value } V \\
\text { (Yuan per ton) }\end{array}$ & 35317.04 & 3409.03 & Difficult to measure & Difficult to measure & 26980.92 \\
\hline
\end{tabular}

According to the calculation of the absolute value of mineral resources from different perspectives, the results obtained are very different. When price volatility is large, the price difference in different years becomes very large (35,700 and 29,400 Yuan per ton in 2017 and 2015 respectively). The calculated absolute value of tin resources also varies greatly (in 2017 and 2015 were 35317.04 and 3400.03 Yuan per ton respectively).This shows that when the price and cost of tin resources change, the absolute value of tin resources will also change, and the magnitude of change will be greater than the price and cost changes. If the price is falling below the cost, then the absolute value of tin resources will become negative. The measurement of the absolute value of tin resources also has no significance. The use of historical high prices in an economic development phase to determine the absolute value of tin resources (2017 is 26,980.92 Yuan per ton).It can effectively avoid the absolute value change brought about by price fluctuations. This is conducive to the protection of tin resources and the full and reasonable use, and also provides a basis for the formulation of mineral resources policies.

The absolute value of the tin resource calculated by the improved method is 26980.92 yuan (On average, the absolute value of the tin resource per year is 2,698.092 Yuan per ton, which can provide reference for government departments to collect taxes). This is the absolute value within the economic and social development phase with an Engel coefficient of $25-33 \%$. This has a long-term expectation and stability. This is conducive to the continuity of the policy related to the absolute value of mineral resources and is conducive to the protection and development of tin resources.

\section{Conclusion}

On the basis of the easy calculation of absolute income, the historical maximum price $P$, the coefficient of economic development stage $\ell$, and the social discount rate $r$ in consideration of the economic and social development stage of mineral resources are considered. It can be more appropriate to reflect the intrinsic, natural, reflecting scarcity and compensating intergenerational characteristics of the absolute value of mineral resources. This reflects the intrinsic properties of the absolute value of mineral resources.

Through case analysis, we can see that the improved method can better reflect future expectations. This avoids drastic changes in accounting results caused by fluctuations in prices and reflects the scarcity of mineral resources due to exhaustion. At the same time, the willingness to pay will be taken into consideration along with changes in the economic and social development stage to avoid the unacceptability of the absolute value of the mineral resources being accounted for. At the same time, we will take into account the willingness to pay for changes in the economic and social development stage. It can be effectively avoided that the absolute value of the mineral resources accounted for is too high to be acceptable. In addition, the social discount rate is set as the social discount rate for the non-ferrous metals mining industry. This makes the choice of parameters in the calculation process more accurate, thus ensuring the accuracy of the calculation results.

The accurate measurement of the absolute value of mineral resources is conducive to realizing the rights and interests of mineral resources owners from an economic perspective. It also helps improve the use of mineral resources and avoid waste. At the same time, it is conducive to the coordination of intergenerational interests, achieving intergenerational equity, and promoting sustainable development.

\section{References}

1. Y. Yuan, Q. Cai, C. Zhao. X. Zhang, Z. Peng, Metal Mine. V39, 18-22 (2009)

2. H. Yang, N. Hu, Y. Tong. D. Chen, China Mining Magazine. 19, 34-37 (2010) 
3. Y. Li, C. Ji, China Mining Magazine. 19, 18-21 (2010)

4. J. Chen, Q. G, Gong, The Theory and Practice of Finance and Economics. 31, 53-57 (2010)

5. Z. Pu, Economic Survey. 129-131 (2008)

6. J. Jiang, Y. Wang, Metal Mine. 113-118 (2017)

7. G. Li, H. Li, China Population, Resources and Environment. 21, 153-159 (2011)

8. J. Li, China Population, Resources and Environment. 12, 11-17 (2002) 